A-22-2020

\title{
DETERMINACIÓN DEL ESTADO HÍDRICO DEL VIÑEDO MEDIANTE EL USO DE IMÁGENES TÉRMICAS Y SU INFLUENCIA EN LA CALIDAD Y PRODUCCIÓN DE LA UVA
}

\author{
Rodríguez-Fernández, M. (1), González, X.P. (2), Fandiño, M.(3), Cancela, J.J.(4)
}

${ }^{1}$ Estudiante predoctoral, Grupo de Investigación Gl-1716 "Proyectos y Planificación" Dpto. Ingeniería Agroforestal. Universidad de Santiago de Compostela. Escuela Politécnica Superior, Campus Universitario s/n, 27002, Lugo. 628757922, marta.rodriguez.fernandez0@rai.usc.es

2 Profesor Contratado Doctor. Grupo de Investigación Gl-2162 "Algoritmos y Modelización Geoespacial" Dpto. Ingeniería Agroforestal. Universidad de Santiago de Compostela. Escuela Politécnica Superior, Campus Universitario s/n, 27002, Lugo. 610968192, xesuspablo.gonzalez@usc.es

${ }^{3}$ Investigadora. Grupo de Investigación GI-1716 "Proyectos y Planificación" Dpto. Ingeniería Agroforestal. Universidad de Santiago de Compostela. Escuela Politécnica Superior, Campus Universitario s/n, 27002, Lugo.98223605, maria.fandino@usc.es

4 Profesor Contratado Doctor. Grupo de Investigación Gl-1716 "Proyectos y Planificación" Dpto. Ingeniería Agroforestal. Universidad de Santiago de Compostela. Escuela Politécnica Superior, Campus Universitario s/n, 27002, Lugo.600940223, javierjose.cancela@usc.es

\section{Resumen}

El contenido de agua en el viñedo, es actualmente un factor de elevada importancia, que afecta directamente a la producción y calidad final de la cosecha, cada vez más exigente por el consumidor. El uso de las nuevas tecnologías en el viñedo, es cada día más utilizado entre los viticultores. El empleo de drones que disponen de cámaras térmicas, permiten analizar información con respecto al estado hídrico del viñedo a lo largo de la campaña, pudiendo establecer de este modo, sistemas de riego eficientes, que aporten a la planta las necesidades hídricas en el momento adecuado, así como una buena gestión de un insumo tan relevante como es el agua.

En el presente estudio, se han realizado dos vuelos de dron próximos a las fechas de envero y floración en la campaña 2019, de un viñedo de 10 ha situado en Rías Baixas y plantado con la variedad 'Albariño'. Con estas imágenes se han podido generar mapas térmicos, que dividen el viñedo en zonas en las que las necesidades hídricas de las plantas muestran un comportamiento homogéneo.

Se midió el potencial hídrico de tallo en 32 puntos de muestreo repartidos sobre una malla de 30x30 m, realizando las mediciones con una cámara de presión Scholander a mediodía solar. El principal objetivo, es el análisis a partir de la temperatura de vegetación y el Crop Water Stress Index (CWSI), siendo los métodos más utilizados para determinar el estado hídrico del viñedo, que permiten evaluar la respuesta de las imágenes térmicas obtenidas con el dron, con la influencia del estado hídrico de la planta en la producción y calidad de la cosecha final. Según los resultados obtenidos, el empleo de imágenes térmicas resulta un buen indicador del estado hídrico del viñedo, que permite realizar un manejo eficiente del mismo, para poder obtener una cosecha con buenos niveles de producción y calidad. 


\section{"Abstract"}

The water content in the vineyard is currently a important factor, that affects the production and quality of the harvest, which is increasingly demanding by the consumer.

The use of new technologies in the vineyard is increasingly used among winegrowers. The use of drones that have thermal cameras, allow analyzing information regarding the water state of the vineyard throughout the campaign, that being able to establish efficient irrigation systems that provide the plant with water needs at the right time, as well as good management of an input as relevant as water.

In the present study, two drone flights have been made close to the dates of ripening and flowering in the 2019 campaign, from a vineyard of 10 ha located in Rias Baixas and planted with 'Albariño' variety.

With these images it has been posible to generate thermal maps, that show water needs balanced zones. Although, the stem water potential was measured at 32 sampling points spread over a 30×30 m mesh, making the measurements with a Scholander pressure chamber at solar noon.

The main objective is the analysis based on the vegetation temperature and the Crop Water Stress Index (CWSI), one of the most widely used methods to determine the water state of the vineyard, which allows evaluating the response of the thermal images obtained with the drone. As well as the influence of the hydric state of the plant on the production and quality of the final harvest. According to the results obtained, the use of thermal images is a good indicator of the water status of the vineyard, which allows efficient management, in order to obtain a harvest with good levels of production and quality.

\section{1) Introducción}

La viticultura de precisión, es una herramienta que está dando a conocer nuevas formas de abordar la producción vitícola, ya que la información y cantidad de datos que genera, ayudan a una mejor interpretación de lo que está sucediendo en una determinada área y en un determinado momento, convirtiéndose en una fuente de información espaciotemporal que tienden a mejorar la toma de decisiones del viticultor (Marchevsky, 2005).

La gestión del agua en el viñedo, es actualmente un factor importante que afecta a la calidad final de la uva. En trabajos como Bellvert et al., 2012 Rios, 2014 y 2016, se ha relacionado el potencial hídrico foliar medido en la viña con el índice CWSI, de forma que se puede considerar el uso de imágenes térmicas procedentes de vuelos de UAVs, como una herramienta útil en la zonificación del viñedo (Candiago et al., 2015; Cancela et al., 2019), que permite al viticultor un manejo diferenciado dentro del mismo.

En este contexto, el uso de imágenes térmicas tiene un importante potencial que permite la estimación de la variabilidad espacial existente dentro del viñedo, permitiendo conocer la temperatura de la 'canopy' que está directamente relacionada con la transpiración de la planta y, por tanto, con el estado hídrico, así como en la influencia de la producción y calidad de la cosecha final, que permite realizar una gestión del viñedo con unos parámetros finales marcados inicialmente por el viticultor (Arnó et al., 2008).

\section{2) Objetivos}

El principal objetivo que se establece en este trabajo, es evaluar en qué medida la adquisición de imágenes térmicas de alta resolución, obtenidas con un vehículo aéreo no tripulado, permiten analizar la variabilidad existente en el estado hídrico de un viñedo.

Para ello, se ha combinado el uso de imágenes térmicas de alta resolución obtenidas mediante un dron, con una escala de trabajo que analiza la evolución del potencial hídrico de tallo, que permite establecer relaciones entre ambos parámetros y analizar su influencia en la producción y calidad de la cosecha en época de vendimia. 


\section{3) Materiales y Métodos}

El estudio se llevó a cabo en un viñedo de la variedad Vitis vinífera cv. Albariño, conducido en espaldera, de 10 ha de extensión y ubicado en Vilagarcía de Arousa (Pontevedra), dividida en cuatro subparcelas. Para la obtención de imágenes térmicas, se empleó una plataforma multirrotor tipo hexacóptero, equipada con una cámara termal Flir Vue Pro $\mathrm{R} 640$, con una focal de $19 \mathrm{~mm}$, geoetiquetando correctamente cada imagen térmica obtenida.

Se realizaron dos vuelos para la campaña 2019, correspondientes con fechas aproximadas a la floración y envero en días despejados ( 25 de junio y 12 de agosto).

Las imágenes fueron procesadas con el sistema de información geográfico "QGIS 3.10 A Coruña", que ha permitido la obtención de mapas del estado hídrico del viñedo para las dos fechas analizadas, permitiendo una posterior clasificación de subzonas dentro de la totalidad del viñedo.

En la parcela a estudio, se estableció una malla de muestreo de $30 \times 30 \mathrm{~m}$, con un total de 32 puntos sobre los que se han tomado datos de potencial hídrico de tallo (stem water potential), mediante una cámara de presión Scholander modelo PMS 600, medido en hojas sanas, bien expuestas y a mediodía solar, los días 25 de junio y 9 de septiembre, para evaluar la respuesta de las imágenes térmicas obtenidas con el UAV. Posteriormente, se calculó el índice de estrés hídrico del cultivo (CWSI - Crop Water Stress Index; Jackson et al., 1981), como indicador del estado hídrico derivado de las imágenes obtenidas, calculado mediante superficies de referencia de las imágenes térmicas, que han permitido la detección del píxel frío y caliente en las imágenes.

En la fecha de vendimia (9 de septiembre), se han determinado parámetros de calidad y producción (producción por planta, número de racimos, grado probable, acidez Total, $\mathrm{pH}$, ácido Málico y ácido Tartárico), que han permitido contrastar estos datos con las zonas de estado hídrico diferencial obtenidas con el potencial de tallo y el CWSI a lo largo del viñedo.

\section{4) Resultados y Discusión}

El mosaicado de las imágenes adquiridas y tratadas, ha permitido comprobar que existen diferencias de temperatura a lo largo de la parcela, presentando además una cierta estructura espacial relacionada con las diferencias en el estado hídrico del viñedo.

La comparativa de las imágenes térmicas obtenidas entre las fechas de floración y envero, han mostrado una clara tendencia de subzonas, en las que el estado hídrico de la planta presenta un comportamiento similar reflejado en los dos vuelos realizados, determinando zonas con mayor estrés hídrico y, por tanto, una mayor temperatura del dosel vegetal (Figura 1).
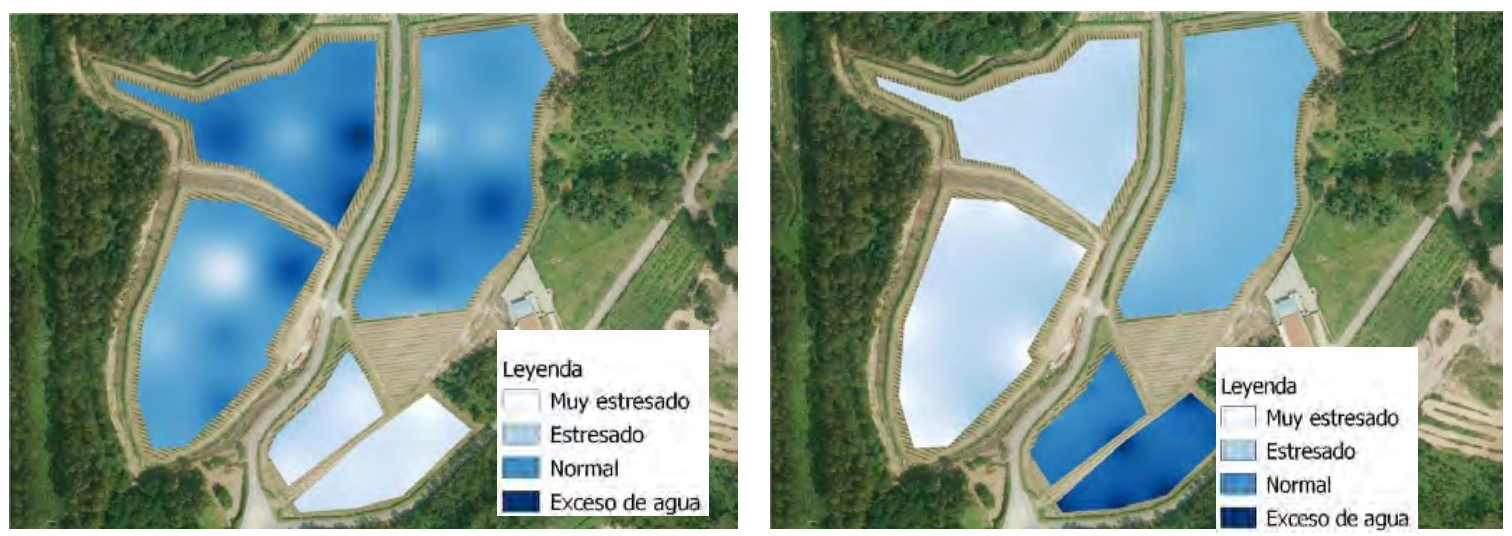

Figura 1. Imágenes térmicas del 25 de Junio y 12 de Agosto de 2019 (de izquierda a derecha respectivamente). 
Con el cálculo del índice CWSI y las medidas de potencial hídrico de tallo se ha observado que existe una correlación lineal entre los datos medidos de potencial hídrico de tallo y el índice de estrés hídrico del cultivo en la floración ( 25 de junio) y envero ( 12 de agosto) de $r^{2}=0,70$ y $r^{2}=0,62$ respectivamente (Figura 2).
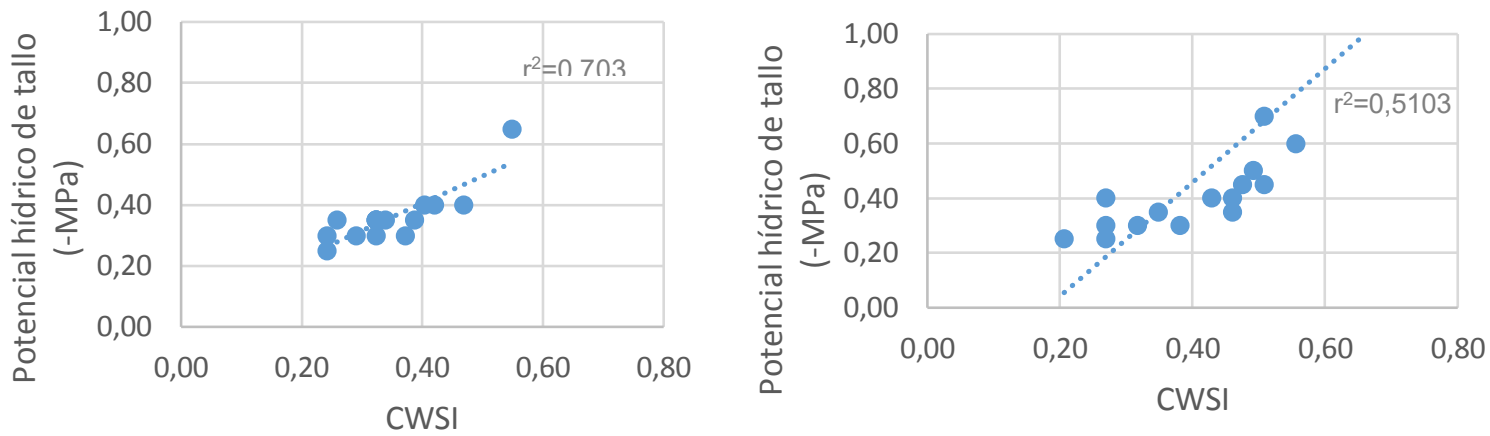

Figura 2. Correlación lineal del potencial hídrico y el CWSI del 25 de junio y 12 de agosto de 2019 (de izquierda a derecha respectivamente).

En cuanto a los parámetros de producción medidos en la vendimia, su comparación con las imágenes térmicas en floración, muestra cómo zonas en las que se observa una tendencia a mayor temperatura de dosel vegetal, obtienen una producción menor, mientras que zonas centrales de la parcela en las que el contenido hídrico de la planta se encuentra en el rango de valores normales, la producción obtenida es mayor (Figura 1 y 3 ).

Por otro lado, en los parámetros de calidad, se ha podido observar un buen balance de parámetros de calidad en los mostos en vendimia para aquellas plantas que no han mostrado un estrés hídrico muy elevado en fechas próximas al envero. En la Figura 4, puede observarse cómo el grado probable del mosto analizado varía a lo largo de la parcela, mostrando zonas con menor grado probable, que también se diferencian en los mapas térmicos obtenidos a partir de las imágenes del dron.

En trabajos como Berni et al., 2009, también se observan relaciones entre el índice CWSI y las medidas de potencial hídrico de tallo que dan a lugar a información útil del estado hídrico del viñedo. Si bien, el manejo diferencial en la parcela en cuanto al contenido de agua durante la campaña, afecta de forma directa a parámetros de calidad de la uva (Girona et al., 2009; Intrigliolo et al., 2012) 


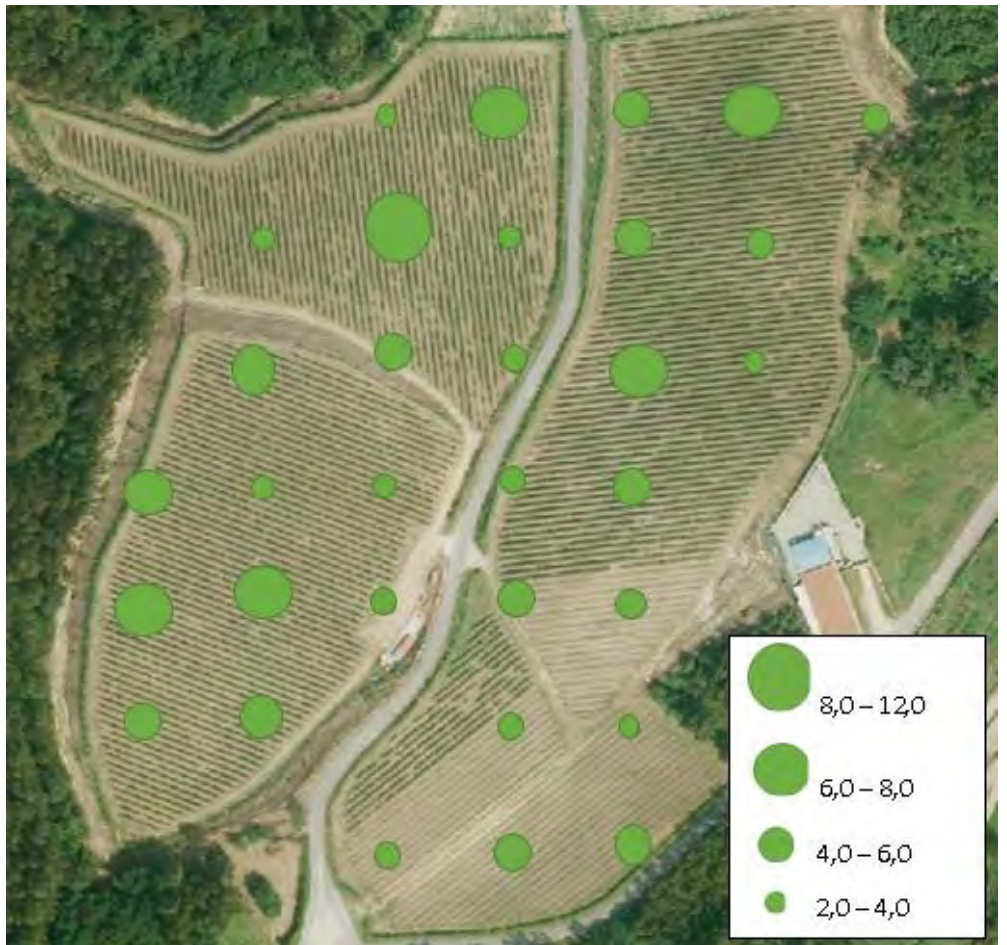

Figura 3. Representación de la producción por planta en fecha de vendimia ( 9 de septiembre 2019).

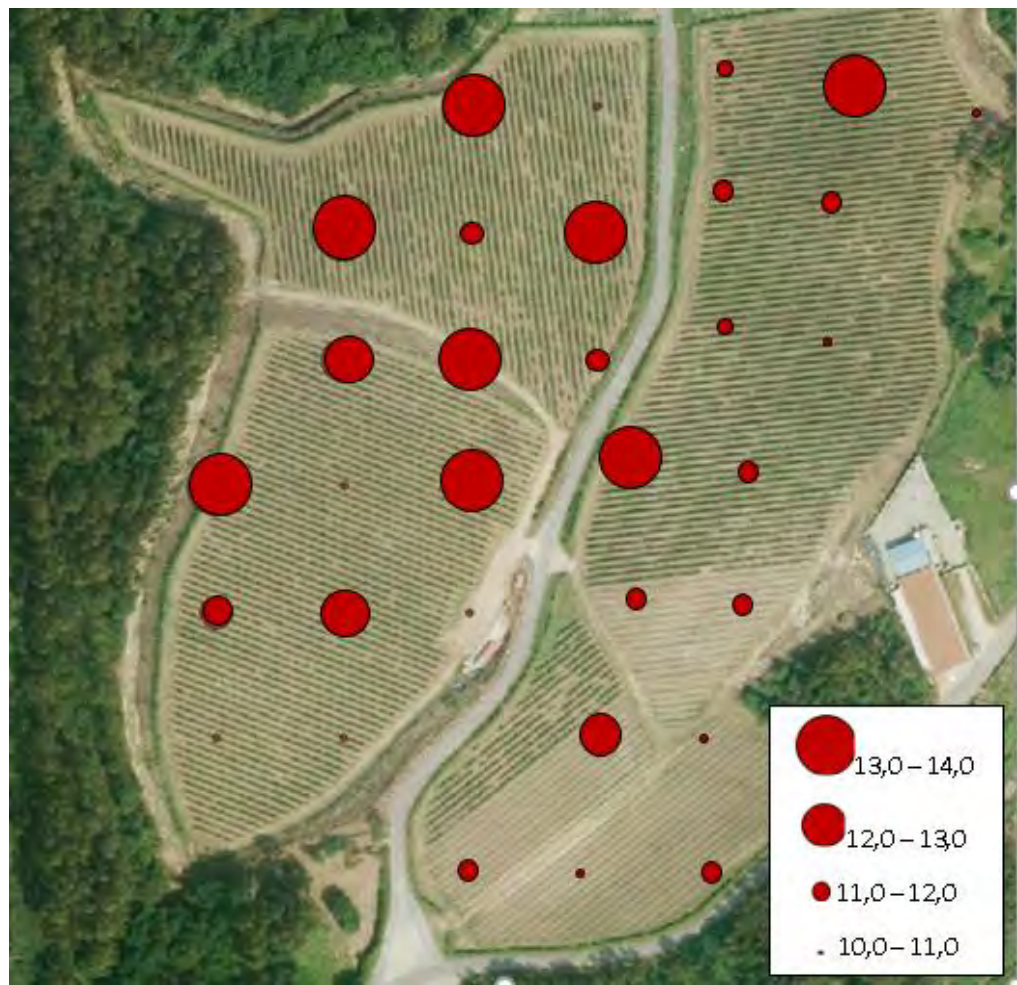

Figura 3. Representación del grado probable obtenido en la parcela en fecha de vendimia (9 de septiembre 2019). 


\section{5) Conclusiones}

El empleo de las imágenes térmicas, puede considerarse una herramienta de gran interés para profundizar en el conocimiento de la variabilidad en el estado hídrico de un viñedo que, condicionará su producción y, por tanto, su potencial cualitativo. Además, ha permitido la caracterización del viñedo intra-parcelario, pudiendo aplicar un tratamiento diferencial según las necesidades hídricas de la planta en cada una de las zonas de la parcela en estudio, que actualmente cuentan con un sistema de riego diferenciado para cada una de ellas.

\section{6) Agradecimientos}

Al proyecto "ALBASOUL" Mar de Frades - Zamora Company.

\section{6) Bibliografía}

Arnó, J., Martínez-Casasnovas, J. A., Blanco, R., Bordes, X., Esteve, J., \& Codorníu, S. A. (2005). Viticultura de precisión en Raimat (Lleida): experiencias durante el período 20022004. ACE-Revista de Enología (on line). http://www.acenologia.com/ciencia73 01.htm

Bellvert, J., Zarco-Tejada, P., Girona, J., Fereres, E. (2014). Riego de precisión en viñedos: manejo de la variabilidad mediante la teledetección térmica.

https://quantalab.ias.csic.es/pdf/riego s 2014.pdf

Berni, J.J., Zarco-Tejada, P.J., Sepulcre-Cantó, G., Fereres, E., Villalobos, F. (2009). Mapping canopy conductance and CWSI in olive orchards using high resolution thermal remote sensing imagery. Remote Sens Environ 113: 2380-2388.

Cancela, J. J., González, X. P., Vilanova, M., Mirás-Avalos, J. M. (2019). Water Management Using Drones and Satellites in Agriculture. Water, 11(5), 874; https://doi.org/10.3390/w11050874

Candiago, S., Remondino, F., De Giglio, M., Dubbini, M., Gattelli, M. (2015). Evaluating multispectral images and vegetation indices for precision farming applications from UAV images. Remote Sensing, 7(4), 4026-4047.

Girona J., Marsal J., Mata M., Del Campo J. and Basile B. (2009). Phenological sensitivity of berry growth and composition of Tempranillo grapevines (Vitis vinifera L.) to water stress. Aust J Grape Wine Res; 15: 268-77.

Intrigliolo D.S., Pérez D., Risco D., Yeves A. y Castel J.R. (2012). Yield components and grape composition responses to seasonal water deficits in Tempranillo grapevines. Irr Sci 2012; 30: 339-49.

Marchevsky, P.L. 2005. Viticultura de precisión. ACE Revista de enología, 63, 1.

QGIS Development Team, 2019 http://qgis.org/es/site/forusers/download.html

Rios, J. B. (2014). El uso de la teledetección de alta resolución como herramienta para realizar un manejo eficiente del riego en viñedos (Doctoral dissertation, Universidad de Córdoba, España).

Ríos, J. B. (2016). Uso de la teledetección de alta resolución con sensores térmicos para el manejo del riego y la variabilidad espacial intralote. Revista Palmas, 37, 267-273. 